\title{
Design of Vehicle Lifting Equipment Using Progressive Methods
}

\author{
Matúš Čuchor ${ }^{*}$, L'uboš Kučera ${ }^{1}$ and Michal Lukáč ${ }^{1}$ \\ ${ }^{1}$ University of Žilina, Department of Design and Mechanical Elements, Univerzitná 8215/1, Žilina \\ 010 26, Slovakia; Email: matus.cuchor@fstroj.uniza.sk, lubos.kucera@fstroj.uniza.sk, \\ michal.lukac@fstroj.uniza.sk
}

\section{*Corresponding Author: Matúš Čuchor}

Received: 10 June 2021; Revised: 19 October 2021; Accepted: 3 November 2021; Published: 30 November 2021

\begin{abstract}
The main objective of this article is to analyse the structural design of tire lifting equipment for tire services. To gain a better insight into the problem, several steps must be taken. The first step is to conduct a market analysis, which involves identifying all available equipment. Several types of lifting devices were distinguished within the development process, which differ from each other in terms of design and power supply. The type of structure and power unit represent the second steps in the design process. This is a critical aspect of the design since the forces necessary to move the system change as a result of these attributes. The design itself is the last step in the device's design. Passenger cars differ from each other by their weight, which is limited to 3.5 tons. Based on the weight, basic strength calculation and dimensioning of the lifting device are carried out. Based on the calculations, the scissor lift device is selected. The lower frame, scissor legs, ramp, mechanical lock, and scissors drive mechanism are five main components of the device. This type of structure is best used with a hydraulic drive unit, which is calculated in the article.
\end{abstract}

Keywords: Structural design, lifting equipment, passenger car

\section{Introduction}

Slovakia's automotive industry is a vital part of the country's economy. The number of cars that needs maintenance is a current and future trend, whether it is a routine tyre and engine oil change or a replacement of worn components. In Slovakia, these services are provided by numerous approved and private car repair shops, where lifting systems represent the most important piece of equipment. There is a wide variety of high- and low-quality equipment available on the market [1-3].

In the process of lifting equipment production, several specific types of lifting equipment are distinguished, which vary in terms of the structure, drive, and materials used. The five main components of the system dealt with in the article include a lower frame, which forms the foundation, 
with pins connecting the scissor legs to it; an arm, which connects it to the rest of the structure; a hydraulic drive unit propelling the entire device, and a mechanical lock, which ensures safe operation. This is the most popular design on the market today [4-5].

The article focuses on the design of a lifting system that can lift cars weighing up to 3.5 tons and is mainly used by tyres service shops. Lifting system must meet several criteria. Must be met by the lifting system. First, it is the ability to lift a vehicle weighing up to 3.5 tons. This category includes smaller city cars, as well as limousines with various wheelbases, ground clearance, and vehicle width. These variables affect the device's complete shape. Another design criterion to be met is the device's minimum stroke of $600 \mathrm{~mm}$, which allows the technician to operate it comfortably. Last but not least, the device safety is a top priority. These are the criteria that must be met by the device [6].

\section{Lifting Device in Use}

Lifting devices are used to lift loads to a height ranging from centimetres to meters in the vertical direction. Lifting devices come in a variety of shapes and sizes. They can all be put to various uses. Since the safety of their use is crucial, safety standards must be in place. STN 270143 is a standard that covers lifting equipment safety, maintenance, and service [7-8].

They are classified into the following categories based on the system of force transmission:

- mechanical,

- pneumatic,

- hydraulic,

- combined.

\section{Dimensional Design of Lifting Device}

The design must be based on the dimensions of the load to be lifted, which is a 3.5-ton vehicle. This category includes small hatchbacks, as well as SUVs and limousines. The wheelbase, ground clearance, and vehicle width are the most important factors to consider when designing the dimensions of the lifting device. These parameters are a part of the standardized vehicle data, as defined by the STN 300026 standard. The lowest ground clearance of vehicles, which begins at 130 $\mathrm{mm}$, is a limiting factor when designing the height of the lifting device. Small cars have a wheelbase of $2500 \mathrm{~mm}$, while limousines have a wheelbase of $3000 \mathrm{~mm}$. The device's width, which is usually about $1500 \mathrm{~mm}$, is the final parameter that affects its shape [9-12].

Figure 1 shows a hatchback car on a lifting device at the bottom dead centre with a wheelbase of $2500 \mathrm{~mm}$ and ground clearance of $140 \mathrm{~mm}$. 


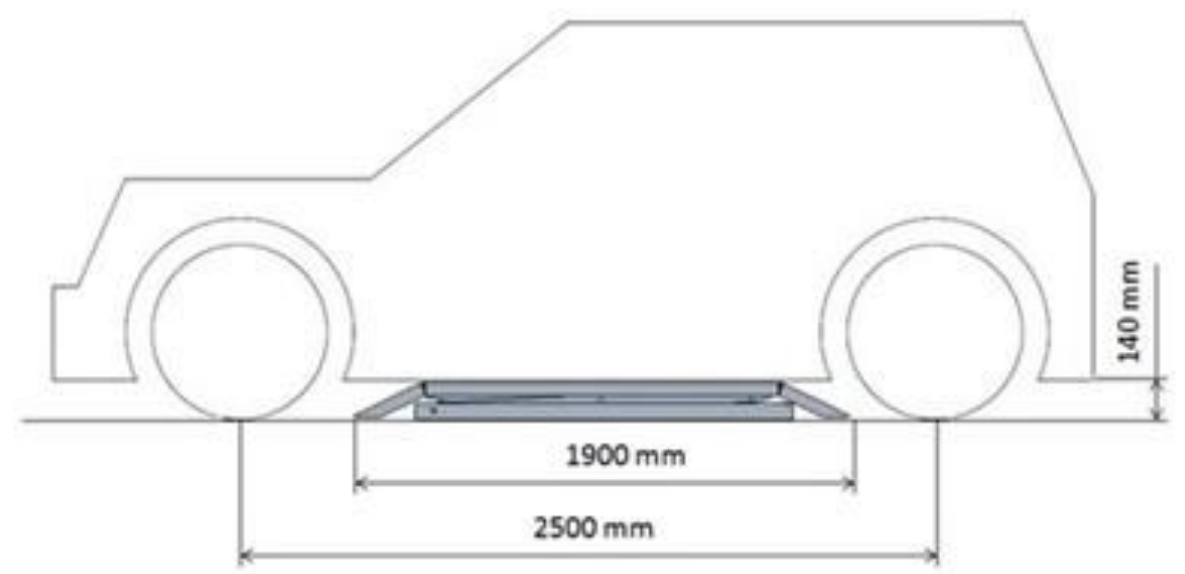

Fig. 1 Car on a lifting device. Source: authors

Figure 2 shows the dimensions of the lifting device at its bottom and top dead centres. Figure 3 shows the view from above.

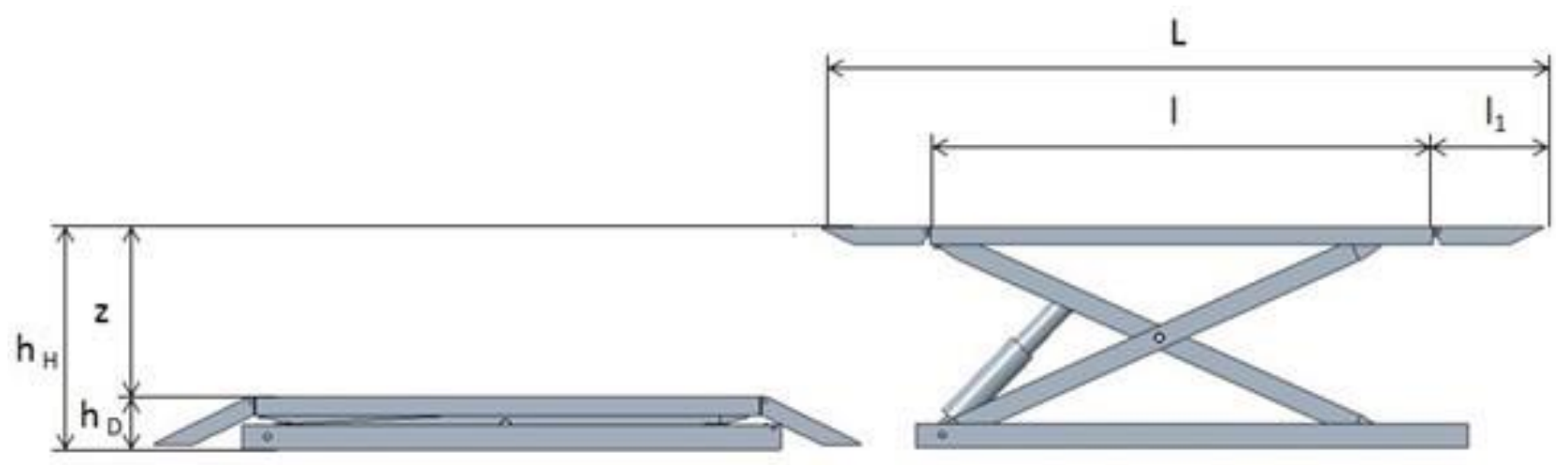

Fig. 2 Dimensions of lifting device: side view. Source: authors

Dimensions of the lifting device when viewed from the side:

$$
\begin{gathered}
\mathrm{h}_{\mathrm{D}}=120,[\mathrm{~mm}] \\
\mathrm{h}_{\mathrm{H}}=602,[\mathrm{~mm}] \\
\mathrm{z}=482,[\mathrm{~mm}] \\
\mathrm{L}=1980,[\mathrm{~mm}] \\
\mathrm{l}=1380,[\mathrm{~mm}] \\
\mathrm{l}_{1}=300,[\mathrm{~mm}]
\end{gathered}
$$

where: $h_{D}, h_{H}, z, L, l, l_{1}$ are dimensions of the device according to Fig 2 [mm]. 


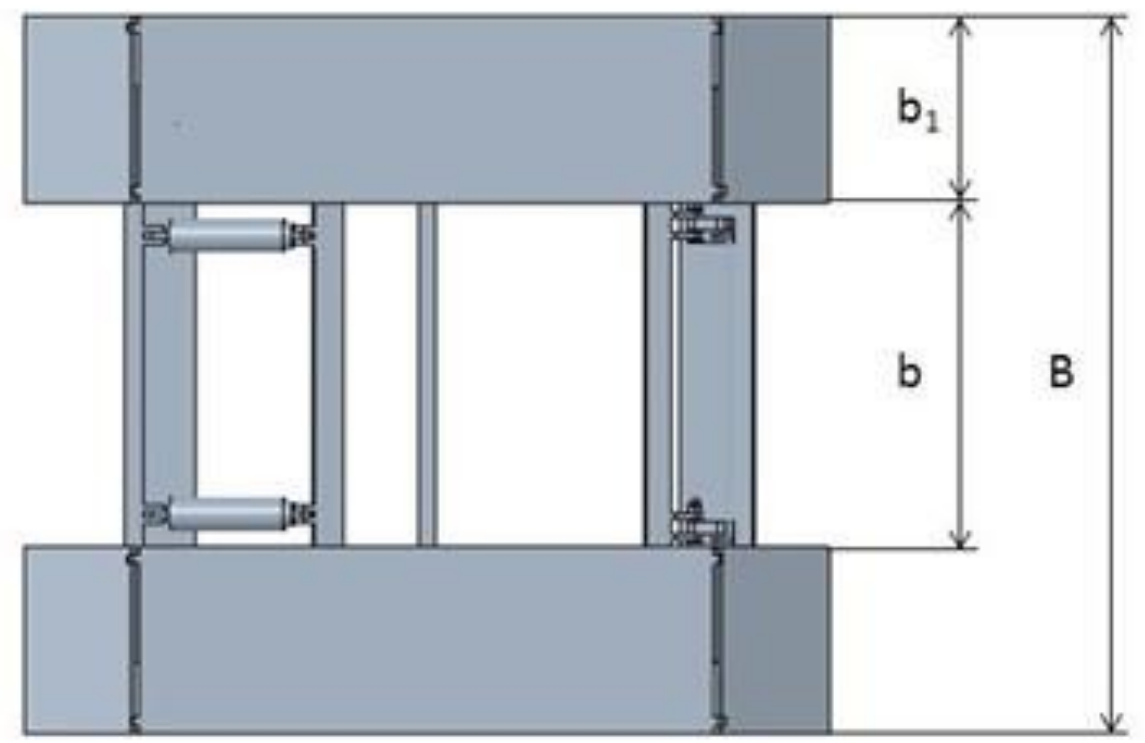

Fig. 3 Dimensions of the lifting device: view from above. Source: authors

Dimensions of the lifting device as viewed from above:

$$
\begin{gathered}
B=1730,[\mathrm{~mm}] \\
b=830,[\mathrm{~mm}] \\
b_{1}=450,[\mathrm{~mm}]
\end{gathered}
$$

where: $\mathrm{B}, \mathrm{b}, \mathrm{b}_{1}$ are dimensions of the device according to Fig 3 [mm].

\section{Forces Acting on the Framework}

The critical factors in the design of the device includes the calculation of the forces, stresses, and reactions of the structure. The results of the calculation determine the stability, protection, and faultless operation of the entire mechanism. The lifting system is a dynamic machine, with individual components moving at different speeds and accelerating at different rates. However, only three positions of the system must be checked for load: the bottom dead centre, top dead centre, and the place where the piston must exert the greatest force to set the device in motion [13-18]. The force used to move the system is calculated in the following chapters. 


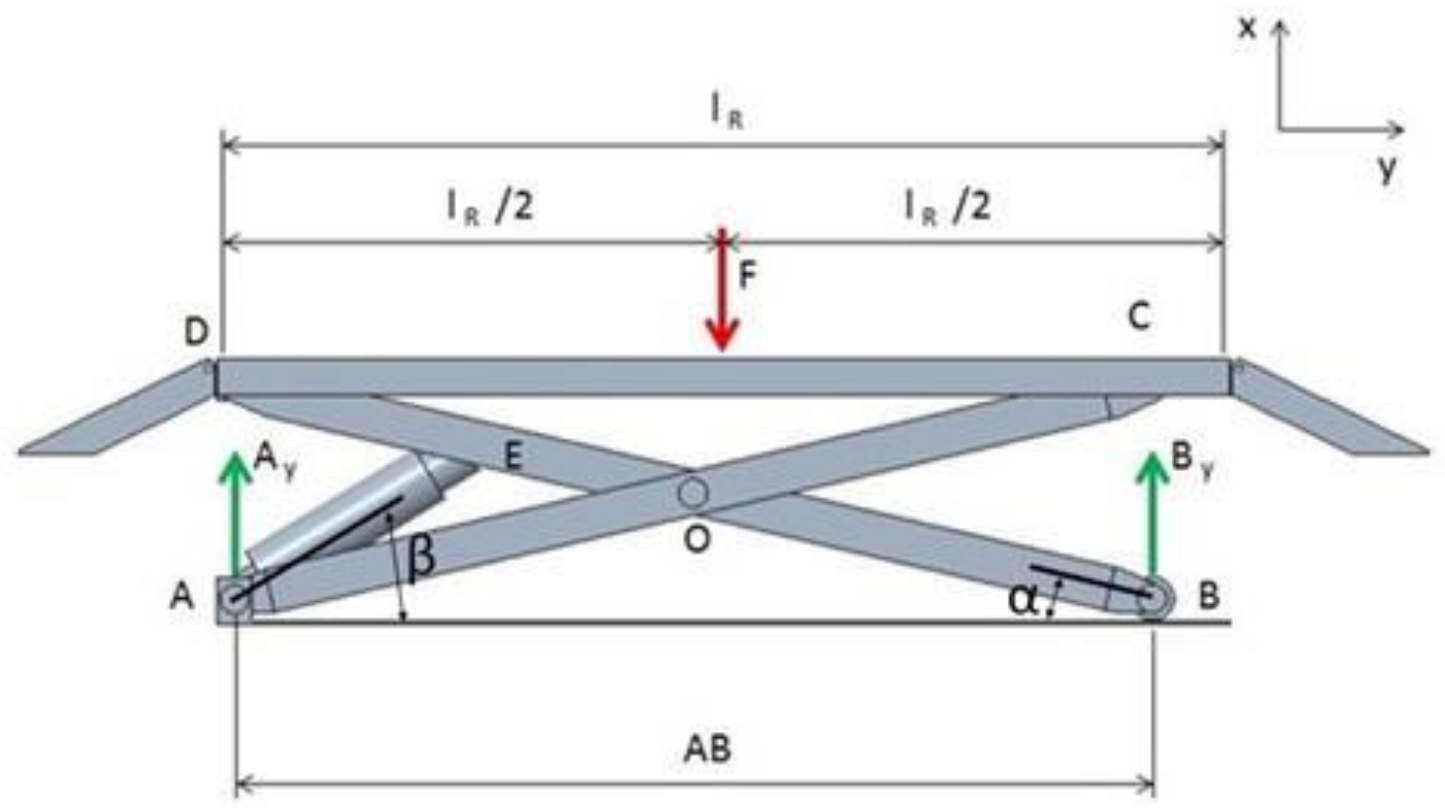

Fig. 4 Device position when the arms are inclined. Source: authors

$$
\begin{gathered}
l_{R}=1370,[\mathrm{~mm}] \\
\frac{l_{R}}{2}=685,[\mathrm{~mm}] \\
A B=1266,681,[\mathrm{~mm}]
\end{gathered}
$$

where: $l_{R}, A B$ are dimensions of the device according to Fig 4 [mm].

$$
F=17167,5,[N]
$$

where: $F$ is force [N].

$$
\sum M_{i A}=0 \rightarrow-F \cdot \frac{l}{2}+B_{y} \cdot A B=0 \rightarrow B_{y}=\frac{F \cdot \frac{l}{2}}{A B} \rightarrow B_{y}=0,512 \cdot F=8789,760[N]
$$

where: $B_{y}$ is force in $\mathrm{Y}$ direction $[\mathrm{N}]$.

$$
\begin{gathered}
\sum F_{i y}=0 \rightarrow-F+A_{y}+B_{y}=0 \rightarrow-F+0,512 F+A_{y}=0 \rightarrow A_{y}= \\
=0,512 . F=8789,760 \mathrm{~N}
\end{gathered}
$$

where: $A_{y}$ is normal force in Y direction [N].

$$
\begin{aligned}
A_{y} & =-D_{y} \\
B_{y} & =-C_{y}
\end{aligned}
$$




\subsection{Static Balance Conditions of BD Arm}

To simplify the calculation, it is sufficient to relax forces on one arm only. This is due to the symmetry of the structure. For this purpose, the BD arm was chosen. In Figure 5 below, the forces acting on the arm are represented by red arrows, green arrows represent reactions.

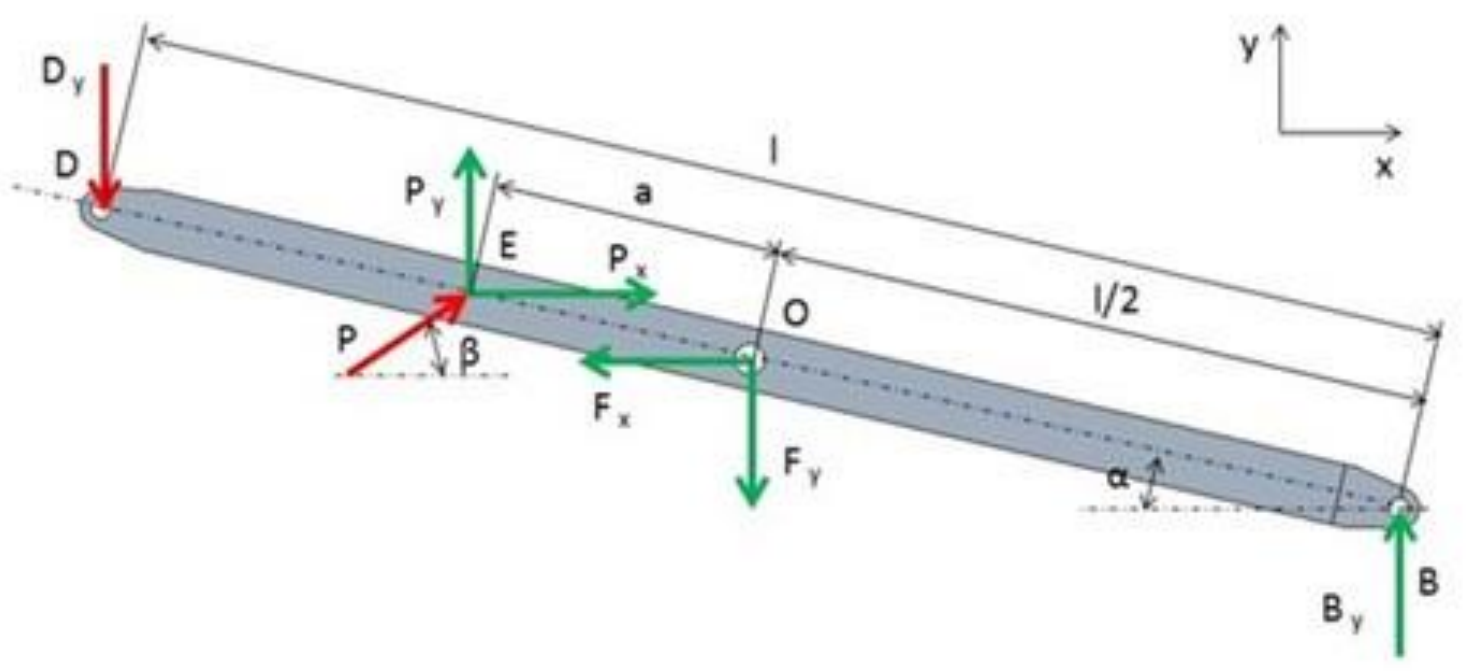

Fig. 5 Forces on the BD arm. Source: authors

Static balance conditions:

$$
\sum F_{i x}=0 \rightarrow P_{x}-F_{x}=0 \rightarrow F_{x}=P_{x} \rightarrow F_{x}=P \cdot \cos \beta
$$

where: $P_{x}, F_{x}$, are forces in the $\mathrm{X}$ direction $[\mathrm{N}], \beta$ is angle $\left[{ }^{\circ}\right]$.

$$
\begin{aligned}
\sum F_{i y}= & 0 \rightarrow-D_{y}+P_{y}-F_{y}+B_{y}=0 \rightarrow F_{y}=P_{y}+B_{y}-D_{y} \rightarrow F_{y}= \\
& =P_{y}+0,512 F-0,488 F \rightarrow F_{y}=P \cdot \sin \beta+0,024 F
\end{aligned}
$$

where: $D_{y}, P_{y}, F_{y}, B_{y}$ are forces in the $\mathrm{Y}$ direction $[\mathrm{N}]$.

Rotation around point B:

$$
\begin{gathered}
\sum M_{i B}=0 \rightarrow D_{y}(l \cdot \cos \alpha)-P \cdot \sin \beta\left[\left(\frac{l}{2}+a\right) \cos \alpha\right]+ \\
+F_{y}\left(\frac{l}{2} \cos \alpha\right)-P \cos \beta\left[\left(\frac{l}{2}+a\right) \sin \alpha\right]+F_{x}\left(\frac{l}{2} \sin \alpha\right)=0
\end{gathered}
$$

where: $P$ is force in the $\mathrm{X}$ direction $[\mathrm{N}], \alpha$ is angle $\left[{ }^{\circ}\right]$.

Equation 8 can be used to calculate the necessary force of the piston at any point by determining the system of equations:

$$
P=\frac{\frac{F}{2}(l \cdot \cos \alpha)}{a \cdot \sin (\alpha+\beta)}
$$

Based on the derived formula for calculating the AE piston force and the known angles of the $\mathrm{BD}$ arm and AE piston from the geometry, Table 1 was compiled, where the forces of the piston $\mathrm{AE}$ 
at individual inclinations of the arm BD are defined. Figure 6 shows a graphical representation of the development of piston force [19-21].

Table 1 Piston forces at various inclinations of BD arm. Source: authors

\begin{tabular}{ccc}
\hline Angle $\alpha$ of the BD arm $\left[^{\circ}\right]$ & Angle $\beta$ of the piston AE $\left[{ }^{\circ}\right]$ & Piston force $[\mathrm{N}]$ \\
\hline 3 & 7.9 & 0 \\
\hline 5 & 13 & 0 \\
\hline 7 & 18 & 22398.602 \\
\hline 9 & 22.7 & 35807.995 \\
\hline 11 & 27.2 & 45419.092 \\
\hline 13 & 31.4 & 53085.423 \\
\hline 15 & 35.3 & 47841.020 \\
\hline 17 & 38.9 & 43389.614 \\
\hline 19 & 42.3 & 41075.039 \\
\hline 21 & 45.7 & 38816.194 \\
\hline 23 & 48.3 & 37031.032 \\
\hline 24 & 49.6 & 36276.123 \\
\hline
\end{tabular}

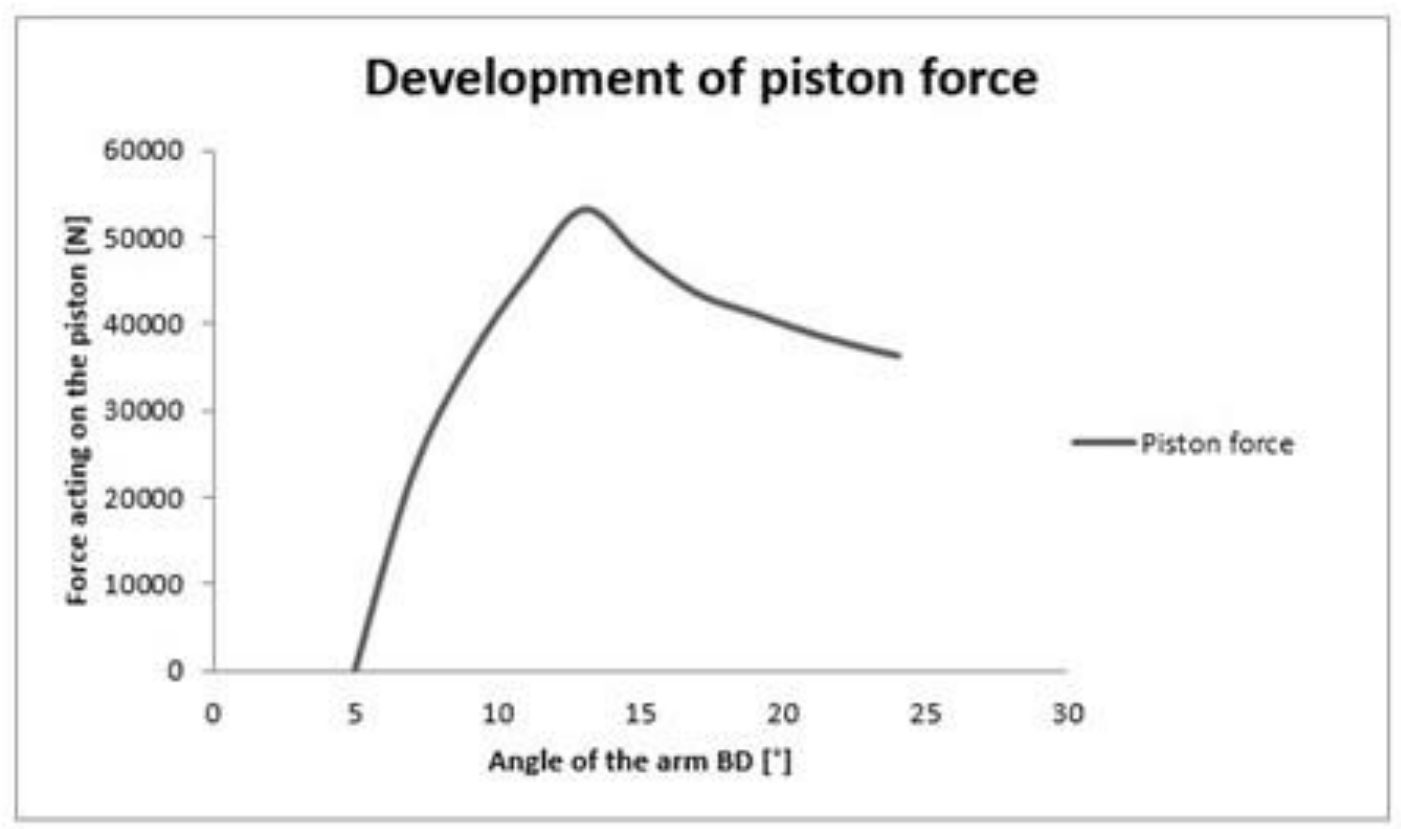

Fig. 6 Piston force development. Source: authors

Figure 7 shows the final solution and configuration of the lifting system. The calculated forces acting on the structure were used to design the individual components of the unit. The system is made up of five basic components that are connected together by pins. The lower frame, to which the scissor 
system is attached, forms the lower part. The device's upper part consists of a ramp that supports the elevated ramps. The device is propelled by pistons. The device's safety is ensured by a mechanical lock that closes the scissor system mechanically and prevents it from moving downwards [22-25].

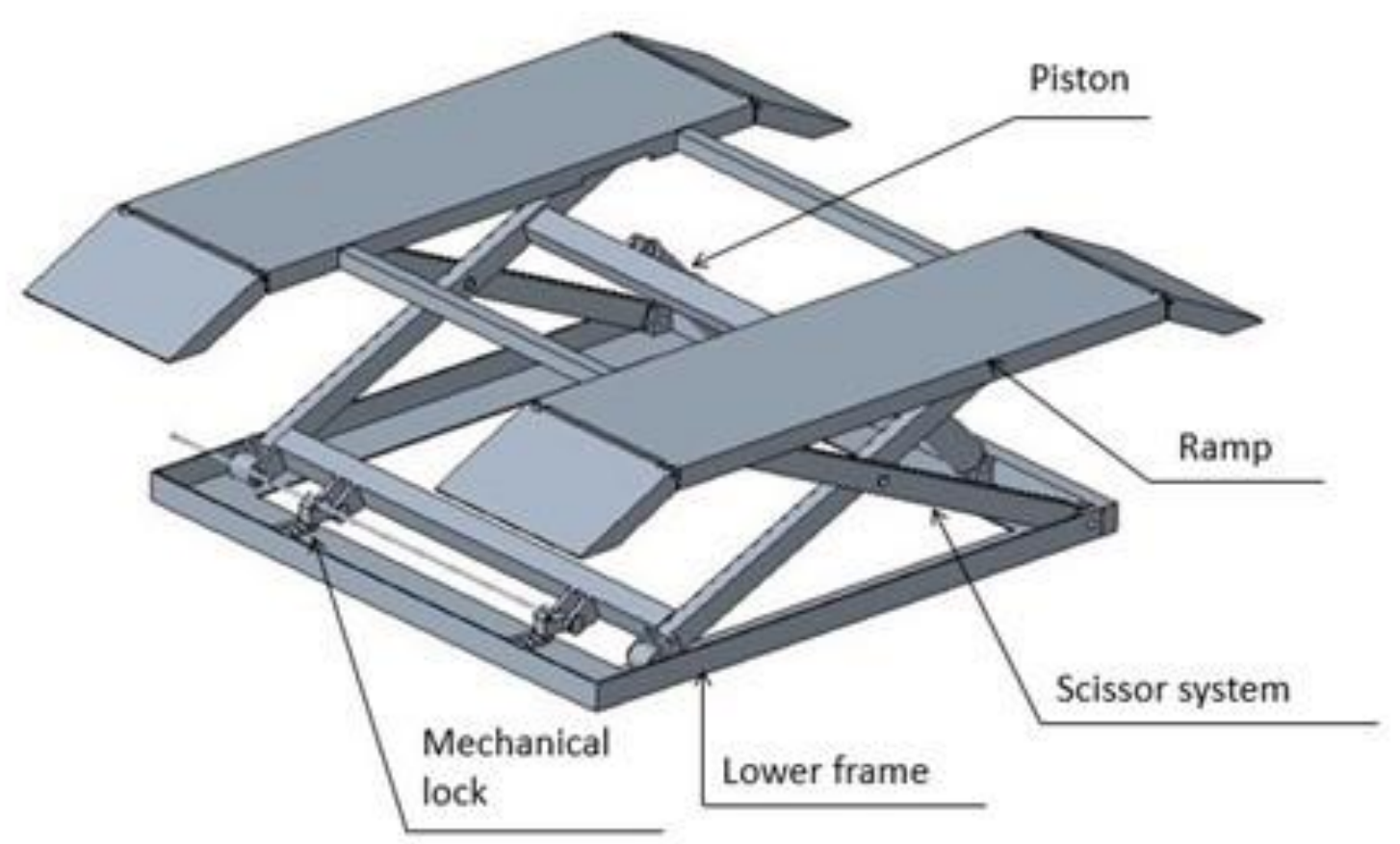

Fig. 7 The lifting device's description. Source: authors

\section{Conclusion}

The objective of the article is to design of a lifting device weighing up to 3.5 tons, primarily for tyre service shops. Prior to designing, it is important to conduct market research to determine what choices and alternatives the market can offer. The survey has shown there are several devices that vary in terms of design or drive. Scissor structure is selected after consulting with the tutor and using personal judgement. Since it outperforms other drives, the hydraulic drive was chosen [26-28].

Prior to the design itself, the basic dimensions of the lifting device, such as the wheelbase, ground clearance, and width of the device, must be determined. The lifting device's dimensions are determined by the parameters defined by the standard STN 30 0026. The length of the ramp is determined by the vehicle's wheelbase. It is variable thanks to the adjustable approach platforms, and thus will suit vehicles with both short and long wheelbases. Another critical consideration in the design is the device's height. The operator must be able to handle the lifting device comfortably, which is enabled by the $600 \mathrm{~mm}$ lift. 
The safety of the device is a top priority. Although the hydraulic piston mechanism is effective, the device still requires a mechanical lock. The lock is intended to keep the unit safe when in use. The mechanical lock's manual operation is easy and comfortable [29].

\section{Acknowledgment}

The research is supported by the Cultural and Educational Grant Agency of the Ministry of Education, Science, Research and Sport of the Slovak Republic under the project No. 045ŽU-4/2021.

\section{References}

[1] Buczaj, A., Krzysiak, Z., Pecyna, A., Caban, J. \& Brumercik, F. (2019). Safety during chemical transport of dangerous goods. Przemysl chemiczny 98(8), 1276-1280. DOI: 10.15199/62.2019.8.13.

[2] Tomasikova, M., Tropp, M., Gajdosik, T., Krzywonos, L. \& Brumercik, F. (2017). Analysis of transport mechatronic system properties. In: 12th International Scientific Conference of Young Scientists on Sustainable, Modern and Safe Transport, 31 May-02 Jun 022017 (pp. 881-886). Amsterdam, Nederland: Elsevier.

[3] Tropp, M., Tomasikova, M., Bastovansky, R., Krzywonos, L. \& Brumercik, F. (2017). Concept of deep drawing mechatronic system working in extreme conditions. In: 12th International Scientific Conference of Young Scientists on Sustainable, Modern and Safe Transport, 31 May-02 Jun 022017 (pp. 893-898), Amsterdam, Nederland: Elsevier.

[4] Tropp, M., Tomasikova, M., Bastovansky, R., Krzywonos, L., Brumercik, F. \& Krzysiak, Z. (2017). Transient thermal simulation of working components of mechatronic system for deep drawing of molybdenum sheets. In: 58th International Conference of Machine Design Departments, 06-08 Sep 2017 (pp. 408-413) Czech Unity Life Sci, Fac Engn, Prague, Czech republic.

[5] Mitka, M., Bastovansky, R., Brumercik, F. \& Ignaciuk, P. (2017). Local resistance of heating molybdenum sheet in a test device. Advances in Science and Technology-Research Journal 11(3), 87-93. DOI: 10.12913/22998624/74182.

[6] Caco, M., Kohar, R., Hrcek, S., Tribula, R. \& Scerba, P. (2017). Use the method of TRIZ in optimizing automated machine for ultrasonic welding. In: 12th International Scientific Conference of Young Scientists on Sustainable, 31 May-02 Jun 022017 (pp. 80-85), Amsterdam, Nederland: Elsevier.

[7] Gramblicka, S., Kohar, R. \& Madaj, R. (2017). Construction design automatically adjustable mechanism for crane forks. In: 58th International Conference of Machine Design Departments (ICMD 2017), 06-08 September 2017 (pp. 100-103). Prague, Czech Republic: Czech University of Life Sciences.

[8] Medvecky, S., Kohar, R. \& Hrcek, S. (2012). Dynamic analysis of cage behavior in a tapered roller bearing. In: 7th International Symposium on Machine and Industrial Design in Mechanical Engineering. 24-26 May 2012 (pp. 45-50). Balatonfured, Hungary.

[9] Majchrak, M., Kohar, R., Kajan, J. \& Skyba, R. (2019). 3D Meshing Methods of Ball-Rolling Bearings. Transportation Research Procedia 40, 784-791. DOI: 10.1016/j.trpro.2019.07.111.

[11] Caco, M., Tribula, R., Scerba, P. \& Kohar, R. (2017). Application of simulation software to optimize construction nodes of ultrasonic welding machines. In: 58th International 
Conference of Machine Design Departments (ICMD 2017), 06-08 September 2017 (pp. 5659). Prague, Czech Republic: Czech University of Life Sciences.

[12] Gramblicka, S., Kohar, R., Majchrak, M. \& Vrabec, M. (2020). Contact Analysis of Selected Toothed Contact of the Two-Stage Front Gearbox. In: 59th International Conference of Machine-Design-Departments (ICMD 2018), 11-14 September 2018 (pp. 263-269). Cham, Switzerland: Springer.

[13] Kohar, R., Stopka, M., Weis, P., Spisak, P. \& Steininger, J. (2020). Modular 3D Printer Concept. In: 59th International Conference of Machine Design Departments (ICMD 2018), 11-14 September 2018 (pp. 483-488). Cham, Switzerland: Springer.

[14] Steininger, J., Hrcek, S., Gajdosik, T. \& Stopka, M. (2017). The optimization procedure of the inner geometry in the spherical roller bearings with regard to their durability. In: 58th International Conference of Machine Design Departments, 06-08 September 2017, (pp. 352355). Czech Univ Life Sci, Fac Engn, Prague, Czech Republic.

[15] Belorit, M., Hrcek, S., Gajdosik, T. \& Steininger, J. (2017). Description of the bearing check program for countershaft gearboxes. In: 58th International Conference of Machine Design Departments (ICMD 2017), 06-08 Sep 2017 (pp. 32-35). Czech Univ Life Sci, Fac Engn, Prague, Czech Republic.

[16] Bistak, M., Medvecky, S. \& Hrcek, S. (2017). The above-ground weighbridge. In: 12th International Scientific Conference of Young Scientists on Sustainable, Modern and Safe Transport, 31 May-02 Jun 2017 (pp. 52-57). Amsterdam, Nederland: Elsevier.

[17] Steininger, J., Hrcek, S. \& Krchnavy, B. (2017). The design of universal loading device for a grinding machines. In: 12th International Scientific Conference of Young Scientists on Sustainable, Modern and Safe Transport, 31 May-02 Jun 2017 (pp. 869-874). Amsterdam, Nederland: Elsevier.

[18] Steininger, J., Hrcek, S., Smetanka, L. \& Skyba, R. (2020). Optimisation procedure of inner geometry in spherical roller bearings with regard to their durability. Scientific Journal of Silesian University of Technology-Series Transport, 173-181. DOI: 10.20858/sjsutst.2020.106.15.

[19] Skyba, R., Hrcek, S., Smetanka, L. \& Majchrak, M. (2019). Strength analysis of slewing bearings. In: 13th International Scientific Conference of Young Scientists on Sustainable, Modern and Safe Transport, 29-31 May 2019 (pp. 891-897). Amsterdam, Nederland: Elsevier.

[20] Belorit, M., Hrcek, S. \& Bistak, M. (2020). Description of the Methodology of the Automated Optimization Process. In: 59th International Conference of Machine Design Departments, 1114 Sep 2018 (pp. 391-398). Cham, Switzerland: Springer.

[21] Skyba, R., Hrcek, S., Smetanka, L. \& Majchrak, M. (2020). Creation of Calculation 3D Model of Slewing Bearing. In: 59th International Conference of Machine Design Departments, 1114 Sep 2018 (pp. 149-157). Cham, Switzerland: Springer.

[22] Steininger, J., Dungel, J., Hrcek, S. \& Gajdac, I. (2020). The Procedure for Reduction of the Acoustic Performance Level of the Spinning Cycle in the Washing Machine. In: 59th International Conference of Machine Design Departments, 11-14 Sep 2018 (pp. 391-398). Cham, Switzerland: Springer.

[23] Jankejech, P., Fabian, P., Broncek, J. \& Shalapko, Y. (2016). Influence of tempering on mechanical properties of induction bents below 540 degrees C. Acta mechanica et automatica 10(2), 81-86. DOI: 10.1515/ama-2016-0013. 
[24] Orman, L.J., Radek, N. \& Broncek, J. (2018). Sintered Mesh Layers for the Production of Efficient Phase - Change Heat Exchangers. Materials Research Proceedings 5, 189-193. DOI: 10.21741/9781945291814-33.

[25] Drbul, M., Martikan, P., Broncek, J., Litvaj, I. \& Svobodova, J. (2018). Analysis of roughness profile on curved surfaces. MATEC Web of Conferences 244, 01024. DOI: 10.1051/matecconf/201824401024.

[26] Liptakova, T., Broncek, J., Lovisek, M. \& Lago, J. (2017). Tribological and corrosion properties of Al-brass. Materials Today: Proceedings 4(5), 5867-5871. DOI: 10.1016/j.matpr.2017.06.060.

[27] Jambor, M., Kajanek, D., Fintova, S., Broncek, J., Hadzima, B., Guagliano, M. \& Bagherifard, S. (2021). Directing Surface Functions by Inducing Ordered and Irregular Morphologies at Single and Two-Tiered Length Scales. Advanced Engineering Materials 23(2), 2001057. DOI: 10.1002/adem.202001057.

[28] Broncek, J., Drbul, M., Stupavsky, M. \& Radek, N. (2017). The application of new rules of GPS in structural product requirement. In: 58th International Conference of Machine Design Departments (ICMD 2017), 06-08 September 2017 (pp. 50-55). Prague, Czech Republic: Czech University of Life Sciences.

[29] Jambor, M., Kajanek, D., Fintova, S., Broncek, J., Hadzima, B., Guagliano, M. \& Bagherifard, S. (2021). Directing Surface Functions by Inducing Ordered and Irregular Morphologies at Single and Two-Tiered Length Scales. Advanced Engineering Materials 23(2), 2001057. DOI: 10.1002/adem.202001057. 